\title{
COMPLICATIONS AND MANAGEMENT OF ENDOSCOPIC SEPTOPLASTY AT A TERTIARY CARE CENTER IN INDIA
}

\section{ENT}

Dr Y B Chhatbar

Professor, Department of Otorhinolaryngology, GCS Medical College, Ahmedabad, Gujarat. India.

\begin{tabular}{ll}
\hline Dr Suktara & Associate Professor, Department Of Otorhinolaryngology, GCS Medical College, \\
Sharma* & Ahmedabad, Gujarat. India. *Corresponding Author
\end{tabular}

PG Student.department OfOtorhinolaryngology, GCS Medical College, Ahmedabad, Dr Prachi M Patel Gujarat. India.

\begin{tabular}{ll}
\hline $\begin{array}{l}\text { Dr Drashty D } \\
\text { Bavarva }\end{array}$ & $\begin{array}{l}\text { PG Student, Department OfOtorhinolaryngology, GCS Medical College, Ahmedabad, } \\
\text { Gujarat. India. }\end{array}$
\end{tabular}

Dr Vaibhav B Patel

PG student, Department of Otorhinolaryngology, GCS Medical College, Ahmedabad, Gujarat. India.

\section{ABSTRACT}

Introduction: Septoplasty for nasal septal deviation is one of the most commonly performed surgeries by the otolaryngologist. Though various surgical techniques have evolved for correction of a deviated septum, complications are still common.

Method: A prospective study of 90 patients of symptomatic nasal septal deviation was done to investigate for development of complications after endoscopic septoplasty. Complications were catagorised into early, occurring within 7 days and late, usually detected within three months after surgery.

Results: Most common early complication was haemorrhage seen in overall $16.66 \%$ of patients. $6.66 \%$ had primary hemorrhage during surgery and $8.88 \%$ had reactionary hemorrhage within 24 hours of surgery. Secondary hemorrhage and septal hematoma was rare(1.1\%). Most common late complication was persistence of subjective symptom of nasal blockage $(15.55 \%)$ followed by nasal synechiae (5.55\%). Septal perforation and vestibular stenosis are less common(1.1\%). CSF leak, saddle nose, nasal tip ptosis or any ocular complications were not seen in any patient.

Conclusion:. Meticulous preoperative planning with precise surgical techniques during endoscopic septoplasty can reduce the risk of complications that may have a profound effect on the functional and aesthetic aspects of a person's life.

\section{KEYWORDS}

Endoscopic Septoplasty, Septal Deviation, complications

\section{INTRODUCTION:}

Deviated nasal septum may be present in up to $60-90 \%$ of the adult population and is aptly described by the phrase "a straight septum is an exception rather than the rule"1 Though the exact cause for deviated septum cannot be defined, in many cases moulding effects on the skull during pregnancy and birth along with trauma are the primary cause. Whether or not a septal deformity deserves surgical attention depends on its impact on nasal function and cosmesis. Nasal septal corrections can be traced back to as early as $3000 \mathrm{BC}$ and finds mention in the ancient Egyptian papyrus. Over the years techniques for correction of a deviated septum have undergone huge transformation in technique and sophistication from digital fracture in ancient times to the currently used endoscopic techniques of septoplasty that can address increasingly complex nasoseptal deformities. Hence the term septoplasty broadly encompasses a number of different techniques that aim to correct septal deviations. ${ }^{2,3}$ Techniques used for correction of septal deviations were initially geared towards septal resections, but more recent techniques lay more emphasis on preservation, realignment, or a combination of the two. The advent of endoscopic septoplasty offered the advantage of better visualization with more precise and accurate manipulation of flaps during dissection of the deviated septal framework. Despite the long history of septoplasty, various surgical techniques are still evolving and complications are reported with most techniques though, their incidence and ratio have undergone reorientation. Septoplasty is one of the commonest operations done by an otolaryngologist in adults. ${ }^{4,5,6}$ Better surgical and anesthesia techniques, have made septolasty a relatively safe procedure and has shifted to being a daycare procedure in most countries. Most common symptoms in patients requiring a septoplasty is airway obstruction and headache while anosmia and snoring being relatively less common. Meticulous preoperative planning with precise surgical techniques can reduce the risk of complications that may have a profound effect on the functional and aesthetic aspects of a person's life. This prospective study was carried out to analyze the complications of endoscopic septoplasty few of which were also combined with turbinoplasty or rhinoplasty as per the need.

\section{MATERIALSAND METHODS:}

This prospective study has been conducted in the department of ENT, at a tertiary care hospital in India between January 2019 to December 2019. All patients with symptomatic nasal septal deviation(NSD) who underwent surgery were included in the study. The diagnosis was based on endoscopic examination of the nose combined with patients' symptoms. Most patients also underwent CT scan to corroborate the clinical diagnosis. The type of NSD was categorized according to the Mladina ${ }^{7,8}$ classification. (Table2) History of nasal allergies, medications and pervious surgeries were documented. All preoperative lab parameters were normal in all patients. Patients who underwent Functional endoscopic sinus surgery for sinus pathologies along with septoplasty were excluded from the surgery. Patients were operated mostly under local anesthesia and iv dexmedetomidine. sedation. Few cases were operated under general anesthesia. Merocel nasal packs was done only in patients with significant bleeding during surgery and a sialistic splint with nasal pack were placed only in patients who underwent a turbinoplasty and in rest of the patients quilting sutures were placed and no packing was done.

Injectable antibiotics, analgesics, proton-pump-inhibitors and antihistamines were administered post operatively. Patients were discharged either on the same day or the next day after removal of pack if done. Xylometazoline nasal drops and saline nasal drops were prescribed on discharge along with antibiotics and oral nasal decongestants. Nasal splints were removed usually a week after surgery on the first follow up. Subsequently patients were called for follow up at 2 weeks, one month and 6 months post surgery. Early complications were defined as those occurring during surgery or upto 7 days of the date of surgery. Late complications were noted in follow up visits and usually appeared within 3 months after surgery. A local ethics committee approval was taken for the study and written informed consent obtained from each patient.

\section{Results and observations:}

Total of 90 patients were included in the study. Number of male and female patients were 81 and 9 respectively with a male/female ratio of 
9:1. The age distribution of patients were between 17 to 48 years. (Table1)

Table.1 Age distribution

\begin{tabular}{|l|l|}
\hline Age in years & No. of cases \\
\hline $10-18$ & 2 \\
\hline $19-35$ & 69 \\
\hline $36-50$ & 19 \\
\hline
\end{tabular}

The type of septal deviation was categorized and noted in each patient according to the Mladina classification. Type 1: unilateral vertical septal ridge in the valve region that does not reach the valve itself, Type 2: unilateral vertical septal ridge in the valve region touching the nasal valve, Type 3: unilateral vertical ridge located more deeply in the nasal cavity, Type 4: S-shaped, Type 5: Almost horizontal septal spur, Type 6: type 5 with a deep grove on the concave side, and Type 7: variation of these types. (Table 2).

Table 2: Type of deviated septum as per the Mladina classification: In type 2-6, the side of deviation is marked $R / L$ (right/left). In type 4 the anterior side is marked as $R / L$

\begin{tabular}{|l|l|ll|}
\hline $\begin{array}{l}\text { Type of Nasal septal } \\
\text { deviation }\end{array}$ & Total (R/L) \\
\hline Type 1 & $\begin{array}{l}\text { Mild deviation in vertical or } \\
\text { horizontal plane that do not } \\
\text { extend along the entire length of } \\
\text { the septum }\end{array}$ & 6 & $(2 / 4)$ \\
\hline Type 2 & Anterior vertical deviation & 36 & $(24 / 12)$ \\
\hline Type 3 & Posterior vertical deviation & 23 & $(18 / 5)$ \\
\hline Type 4 & S shaped septum & 10 & $(4 / 6)$ \\
\hline Type 5 & $\begin{array}{l}\text { Horizontal spur on one side with } \\
\text { or without high deviation to the } \\
\text { opposite side }\end{array}$ & 9 & $(6 / 3)$ \\
\hline Type 6 & $\begin{array}{l}\text { Type 5 with a deep groove on the } \\
\text { concave side }\end{array}$ & 4 & $(1 / 3)$ \\
\hline Type 7 & $\begin{array}{l}\text { Combination of more than one } \\
\text { type. }\end{array}$ & 2 & \\
\hline
\end{tabular}

Six patients had caudal dislocation and two patients also had a visible external nasal deformity that required rhinoplasty correction. All patients underwent an endoscopic septoplasty. Out of the total 90 patients operated, concurrent inferior turbinate hypertrophy that resisted any form of medical treatment was seen in 5 patients requiring some form of turbinoplasty using methods such as radiofrequency ablation, submucosal diathermy or partial of complete resection with a microdebrider. Two patients underwent septorhinoplasty for external deviation.(Table 3 )

Table. 3 Type of operations done in this period for NSD

\begin{tabular}{|l|l|}
\hline Types of operation & No. of cases $(\mathbf{n}=\mathbf{9 0})$ \\
\hline Septoplasty & 83 \\
\hline Septoplasty\& turbinoplasty & 5 \\
\hline Septorhinoplasty & 2 \\
\hline
\end{tabular}

Complications of surgery were noted and separately categorized as early, within 7 days of surgery ((Table $4 \&$ Fig 1$)$ Any complication after 7 days were considered as subacute or late complications and were usually noticed within 3 months after surgery (Table $5 \&$ Fig 2) Most common early complication was haemorrhage seen in 15 patients $(16.66 \%)$ of which $6(6.6 \%)$ patients had primary hemorrhage at the time of surgery and $8(8.88 \%)$ patients had reactionary hemorrhage within 24 hours of surgery. 1 patient each had secondary hemorrhage and septal hematoma. Late complications included persistence of symptoms and dissatisfaction in 14 patients $(15.55 \%)$, of which nasal synechia in 5 patients $(5.55 \%)$ and septal perforation and vestibular stenosis in one patient respectively $(1.11 \%)$. Other reported complications such as CSF leak, tooth anesthesia, structural deformities such as saddle nose and nasal tip ptosis or any ocular complication were not seen in our study.

Table.4 Early complications of septoplasty within 7 days

\begin{tabular}{|l|l|}
\hline Early complications & No. of cases $(\mathbf{n}=\mathbf{9 0})$ \\
\hline Primary haemorrhage & $6(6.6 \%)$ \\
\hline Reactionary haemorrhage & $8(8.8 \%)$ \\
\hline Secondary haemorrhage & $1(1.11 \%)$ \\
\hline Septal haematoma & $1(1.11 \%)$ \\
\hline
\end{tabular}

Early complications of septoplasty

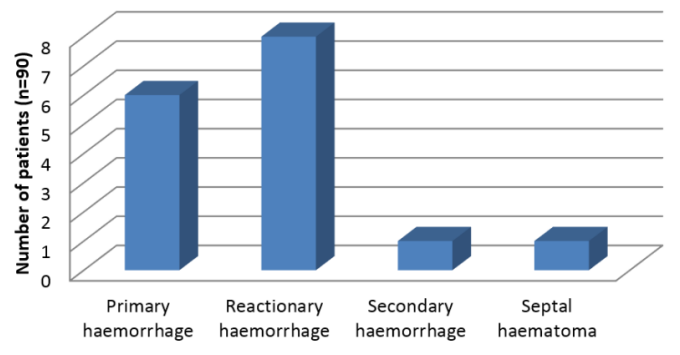

Fig 1 : Early complications of septoplasty

Table.5 shows different late complications found within 3 months from operation

\begin{tabular}{|l|l|}
\hline Late compications & No. of cases. $(\mathbf{n}=\mathbf{9 0})$ \\
\hline Persistence of symptoms & $14(15.55 \%)$ \\
\hline Synechia & $5(5.55 \%)$ \\
\hline Vestibular stenosis & $1(1.11 \%)$ \\
\hline Septal perforation & $1(1.11 \%)$ \\
\hline & \\
\hline
\end{tabular}

\section{Late complications of septoplasty}

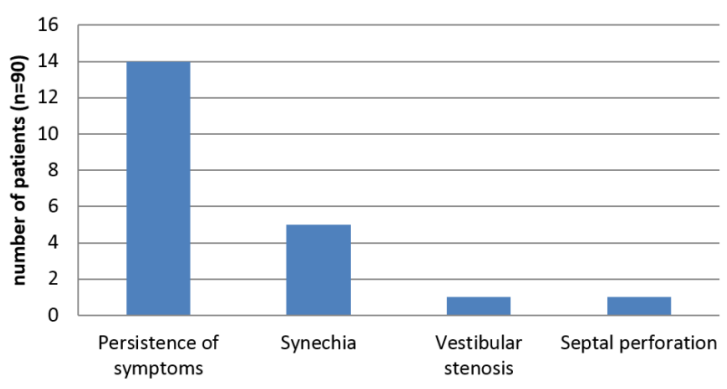

Fig 2 : Late complications of septoplasty

\section{DISCUSSION:}

Nasal Septal Deviation is a widespread problem that can have substantial quality of life consequences. Septoplasty is usually done to offer qualitative and quantitative advantage to those with nasal blockage due to NSD.

In the present study several complications that might be associated with Septoplasty alone or with concurrent turbinectomy or rhinoplasty have been investigated. The patients were assessed regularly for six months post surgery. The most common early complication encountered was hemorrhage. Primary haemorrhage at the time of surgery in our study was common in patients with history of hypertension specially when operated under local anesthesia. Primary hemorrhage often resulted in compromising the surgical field during septoplasty. Poor injection technique or mucosal injury are the other causes of primary hemorrhage. Ping et $\mathrm{al}^{10}$ reported that pre operative tranexemic acid could effectively reduce bleeding during nasal surgery though it was not used in any of our patients. Intra operative bleeding may prolong the procedure as well as reduce the success of the procedure, hence the need for a meticulous pre operative assessment and preparation of such patients with good intra operative control of blood pressure. Post-operative oozing in the period immediately after surgery is very common and cannot necessarily qualify as a complication but rather is something to be expected. In our study 8 cases of significant reactionary haemorrhage requiring intervention in the form of nasal packing or an additional dose of haemostatic drug like Tranexemic acid or antihypertensive medications were seen. 3 out of the 8 patients with significant post operative hemorrhage also had a turbinoplasty done. Increased risk of minor bleeding is reported in cases where osteotomies or turbinectomy were performed concurrently $y^{3,11,12}$. One patient developed septal haematoma on $2^{\text {nd }}$ post operative day, which was successfully managed. A septal haematoma may be seen when either a quilting stitch is not used or nasal packing is not placed. The use of fibrin glue in septal surgery has been advocated by Danesharad who suggested that it is an effective, comfortable and inexpensive way to prevent hematoma formation. ${ }^{13,14}$

The most common late complication of septoplasty is persistence in 
the subjective complaint of nasal obstruction seen in $15.6 \%$ of our patients. Approximately $20-30 \%$ of the patients who undergo septoplasty find that their symptoms are not corrected adequately. Persistent septal deviation, septal perforation, untreated nasal valve insufficiency, inferior turbinate hypertrophy or nasopharyngeal pathologies are the main reasons for it. Patients who undergo nasal septoplasty may have coexisting diseases such as allergy, asthma or obstructive sleep apnea. It is important that allergic and asthmatic patients are treated medically also postoperatively to optimize the outcome. A subset of these patients may need to undergo revision for definite correction of an under corrected NSD or Turbinate hypertrophy. Revision surgery is however more difficult and extra caution and exact planning is of paramount importance. ${ }^{15,16,17}$

Intranasal adhesion or synechia development is an important complication in the post-operative phase of nasal surgery with an incidence which varies from $10 \%$ up to $36 \%{ }^{18}$ In our study we got only 5 cases of synechia(5.5\%). Excision of the synechia was done under local anesthesia, followed by application of silastic splints; splints were removed after 10-12 days. There was no recurrence of synechia in these patients. Trauma to the lateral nasal wall skin and mucosa, if coupled with damage to the septal mucosa, may pre-dispose to this and careful use of instruments is a relevant factor. When combined procedures on the septum and turbinates are necessary, the silastic nasal splint should be used. In a study to determine the frequency of nasal synechia after septoplasty it was found that that the frequency of synechia between the splinted and non-splinted nose after septoplaty was $0 \%$ and $10.6 \%$ respectively. However, the patients with splints had more pain and nasal discomfort than the non-splint group. Hence routine use of splints in all cases of septoplasty may not be warranted. A curved needle instead of popular straight Keith needle should be used for mattressing the mucoperichondrial flaps reducing the potential for lateral nasal wall or turbinate injury, and formation of intranasal synechia.

Nasal stenosis is a rare complication of septoplasty. In our series one patient started developing it 3 months after the surgery. Excessive incisions inside the nasal vestibule, particularly if coupled with excision of vestibular skin, will lead to stenosis and narrowing of the airway which may be very severe. It is a very difficult problem to resolve and usually requires several months of prosthetic support in order to counteract the recurrence of internal scarring and shrinking. ${ }^{19}$

In our study, we had one case of septal perforation $(1.11 \%)$ which was posteriorly placed and asymptomatic and did not require any treatment. Anterior septal perforation may cause symptoms such as nasal obstruction, whistling, epistaxis, crusting, pain, rhinorrhea, or even chronic rhinosinusitis. Perforations result from mucoperichondrial tears, particularly when they are bilateral and overlapping. The reported incidence of septal perforation after septoplasty ranges from $0.5 \%$ to $3.1 \%$ Only symptomatic perforations require treatment. Medical treatment with nasal irrigation and ointments can reduce crusting and dryness. Other methods include silicon or magnet based buttons or a formal surgical correction. Though numerous techniques have been described, such as external approach, intranasal, endoscopic, midfacial degloving or sublabial approach, with the use of various grafts and flaps, endoscopic repair has gained popularity over the last decade over all other techniques. Factors predictive of success include size, site, bilaterality of flap coverage and grafting material. ${ }^{11,20,21,22}$

\section{CONCLUSION:}

Septal surgery is one of the commonest performed surgeries in ENT. If not performed meticulously it may give rise to several complications and may worsen the quality of life in the long run. Of all the complications most important and troublesome complications intra operative bleeding, synechia and persistence of symptoms. Proper techniques and good post-operative care keep complications at bay.

Due to good surgical and anesthesia technique septoplasty is a relatively safe procedure to perform

\section{Compliance with Ethical Standards:}

- Conflict of Interest: There is no conflict of interest in this paper. nasal septum-A historical overview, Arch Med Health Sci 2018; 6;293-7

Delaney, Sean. (2018). Evolution of the Septoplasty: Maximizing Functional and Aesthetic Outcomes in Nasal Surgery. M J Otol. 1(1): 004

4. Ketcham AS, Han JK (2010) Complications and Management of Septoplasty. Otolaryngol Clin North Am. 43(4):897-904. https:// doi: 10.1016/j.otc.2010.04.013

5. Bothra, R, Mathur NN (2009) Comparative evaluation of conventional versus endoscopic septoplasty for limited septal deviation and spur. J Laryngo Otol.123(7):737-41. https://doi: 10.1017/S0022215108004192. Epub 2008 Dec 2.

6. Bien JD, Skarżyński PH, Gwizdalska I, Łazęcka,K, Skarżyński H (2018) Complication in septoplasty based on a large group of 5639 patients Eur Arch Otorhinolaryngol. 275(7): 1789-1794. https:// doi: 10.1007/s00405-018-4990-8

7. Teixeira J, Certal V, Chang ET, Camach M (2016) Plastic surgery international: Nasal Septal Deviations: A Systematic Review of classification systems. Vol 2016. https://doi.org/10.1155/2016/7089123

8. Rao JJ, Kumar EC,Babau KR, Chowdary VS, Sing J, Rangamani SV (2005) Classification of nasal septal deviations-relation to sinonasal pathology. Indian Journal of Otolaryngol Head and Neck Surg, , Vol 57:3:199-201 https:// doi.org: 10.1007/BF03008013

9. Most SP , Rudy SF (2017) Septoplasty: Basic and Advanced Techniques Facial Plast Surg Clin North Am. 25(2):161-169. https://doi.org 10.1016/j.fsc.2016.12.002

10. Ping WD, Zhao QM , Sun HF, Lu HS, Li F (2019) Role of tranexamic acid in nasal surgery:A systemic review and meta-analysis of randomized control trial. Medicine (Baltimore) $98(16)$ https://doi.org/10.1097/MD.0000000000015202

11. Han JK, Stringer PS, Richard M. Rosenfeld RM (2015) Clinical Consensus Statement: Septoplasty with or without Inferior Turbinate Reduction. $153: 5$ : 708-720 https://doi.org/10.1177/0194599815606435

12. Becker GD. (2003)Septoplasty and Turbinate Surgery. Aesthetic Surg J ; 23:393-403

13. Choi SY, Lee HY, Chang DS, Choi MS (2017) Postoperative Septal Abscesse According to the Techniques of the SeptoplastyJ Rhinol 24(2):74-80 https://doi.org/10.18787/jr.2017.24.2.74

14. Daneshrad P, Chin GY, Rice DH (2003) Fibrin glue prevents Complications of Septal Surgery: Findings in a series of 100 patients. Ear Nose Throat J. 82(3):196-7

15. Bugten V, Nilsen AH, Thorstensen WM, et al. (2016) Quality of life and symptoms before and after nasal septoplasty compared with healthy individuals. BMC Ear Nose Throat Disord 16: 13. https://doi.org/10.1186/s12901-016-0031

16. Serhan D, Sahan M, Deveer M, Erdogan S et. al (2016) The Causes of Persistent and Recurrent Nasal Obstruction after Primary Septoplasty.J Craniofac Surg 27(4):1: 828830 https://doi.org/ 10.1097/SCS.0000000000002505

17. Kuduban O, Bingol F, Budak A, Kucur C (2015) The Reason of Dissatisfaction of Patient after Septoplasty Eurasian J Med. 47(3): 190-193. https:// doi.org/ 10.5152/ eurasianjmed.2015.18

18. Coelho RG, Brandao FH, Carvalho MR et al (2008) Frequency of Nasal Synechia after Septoplasty with Turbinectomy with or without the Use of Nasal Splint. International archives of Otorhinolaryngology. Intl. Arch. Otorhinolaryngol., 12(1):24-27

19. Blandini, Daniele M.D.; Tremolada, Carlo M.D.; Beretta, Maurizio M.D.; Mascetti, Mario M.D (1995) Iatrogenic Nostril StenosisAesthetic Correction Using a Vestibular Labial Mucosa Flap. Plastic and Reconstructive Surgery, 95(3):569-571

20. Quinn JG, BonaparteJP, KiltySJ (2013) Postoperative management in the prevention of complications after septoplasty: a systematic reviewLaryngoscope 123(6):1328-33 doi: 10.1002/lary.23848. Epub 2013 Apr 26.

21. Yildize E, Kahveci OK (2019) What are the Factors Leading to Nasal Septa Perforations after Septoplasty? Otolaryngol Rhinol 5:065 https:// doi.org10.23937/ 2572-4193.151006

22. Cassano M. (2017) Endoscopic Repair of Nasal Septal Perforation. Acta Otorhinolaryngol Ital 37(6): 486-492 https:// doi.org 10.14639/0392-100X-1313

\section{REFERENCES}

1. Shari D. Reitzen, MD; Wayne Chung, MD; Anil R. Shah, MD Nasal septal deviation in the pediatric and adult populationsent-Ear, Nose \& Throat Journal a March 2011

2. Subramanium V, Basheer M, Hosagadde RS, Evolution of correction of the deviated 